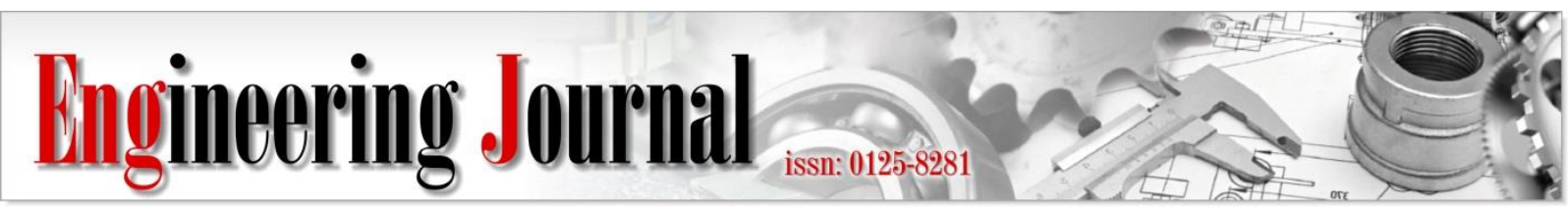

Article

\title{
Impacts of Lateral Boundary Condition Resolution in Tropical Urban Climate Modelling for Kuala Lumpur
}

\author{
Nurul Amirah Isa ${ }^{1}$, Siti Aekbal Salleh ${ }^{1,2, *}$, Wan Mohd Naim Wan Mohd ${ }^{1}$, \\ Maggie Chel Gee Ooi ${ }^{3,4}$, Andy Chan ${ }^{5}$, and Md Amirul Islam ${ }^{5}$
}

1 Centre of Studies for Surveying Science and Geomatics, Faculty of Architecture, Planning and Surveying, Universiti Teknologi MARA, 40450 Shah Alam, Selangor, Malaysia

2 Institute for Biodiversity and Sustainable Development, Applied Remote Sensing and Geospatial Research Group, Universiti Teknologi MARA, 40450 Shah Alam, Selangor, Malaysia

3 Department of Atmospheric Sciences, National Central University, 32001 Chung-Li, Taiwan

4 Institute of Climate Change, National University of Malaysia (UKM), 43600 Bangi, Selangor, Malaysia

5 Department of Civil Engineering, Faculty of Engineering, University of Nottingham, Jalan Broga, 43500

Semenyih, Selangor, Malaysia

*E-mail: aekbal@uitm.edu.my (Corresponding author)

\begin{abstract}
Choosing the best LBCs is still debated among researchers due to the errors resulted. However, several recommendations have been documented to control the errors propagated by LBCs. One of the recommendations is employing higher resolutions LBCs. In the present, many LBCs are developed with various resolutions; spatially and temporally, for many applications but no claims regarding the best LBCs for tropical climate modelling have yet been documented. Therefore, this study intends to analyse the impacts of lateral boundary condition resolution during numerical downscaling within a tropical city. This study serves as a site-specific investigation to determine the suitable LBCs for the focused study area. Two widely used LBCs with different resolutions were utilized to initiate the Weather Research and Forecasting (WRF) simulation model. The performances of the two LBCs were compared using statistical tests and analyses. The study has found that the LBC with higher resolutions excels the other LBC during inter-monsoon season. Nevertheless, it was identified that both LBCs were able to provide reliable reconstruction of the tropical climate condition of the Kuala Lumpur City as portrayed by similar results obtained. Thus, it is concluded that both LBCs can be employed in numerical downscaling for tropical urban regions similar to the Kuala Lumpur City.
\end{abstract}

Keywords: Lateral boundary condition, resolution, WRF, tropical urban, Kuala Lumpur.

ENGINEERING JOURNAL Volume 25 Issue 1

Received 6 June 2020

Accepted 25 November 2020

Published 31 January 2021

Online at https://engj.org/

DOI:10.4186/ej.2021.25.1.165 


\section{Introduction}

Obtaining the climate datasets is one of the main obstacles for studying climate condition. The evolution of technology has brought new approach of obtaining climate datasets which is through the implementation of numerical modelling [1]. Nowadays, general climate models (GCM) are used for climate studies worldwide. There are many GCMs developed by various institution to cater the needs which ensemble the climate circulation pattern via numerical modelling technique. However, the GCMs offer poor spatial resolutions for various scales of climate assessments especially for regional-scaled studies. The models succeed in resolving large-scale forcing but unable to represent the local climate impacts [2]. Due to this, regional climate models (RCM) are developed to simulate the GCMs using higher resolution nests over the targeted area [3]. This approach can account for the local climate impacts within the finer domains. In the urge for regional climate studies, numerical simulation models are often employed as a solution in obtaining climate datasets. These models are developed using complicated mathematical and physics theories (known as physics options) in order to resemble the complexity of climate.

Six physics options are included in these models namely microphysics, planetary boundary layer (PBL), long and short-wave radiation, surface layer, land surface layer and cumulus parameterization. Microphysics involves the theory of atomic, clouds and others to define the behaviour of the surrounding environment [4]. The PBL is included to set up the lowest atmospheric condition which directly influenced by the its contact to the planetary surface since this layer has rapid fluctuations of physical quantities such as temperature, moisture, flow velocity and others creating turbulence [5]. The influence of emissivity, absorption and surface fluxes within the atmosphere is modelled using long and shortwave radiation schemes [6]. Cumulus parameterisation has been developed over few decades to model the clouds within the atmosphere. The clouds are significantly influenced the climate system in the distribution of sensible and latent heat and momentum, reflection, absorption and emission of radiation, precipitation, and modification of radiation and planetary boundary layer processes [7]. In modelling regional climate, the interactions of the earth features towards the atmosphere are very crucial since they can alter the original concept of physics and dynamics in the atmosphere making every place on the Earth surfaces to be climatically unique [8]. Surface layer is included to solve the surface layer characteristics that includes turbulence, sensible heat flux, surface moisture flux and others [9].

Using the physics options, numerical models are used to downscale global-scaled weather datasets into regional scales which requires the usages of lateral boundary condition (LBC) for model initializations. In numerical models, the LBC utilized represents the Earth surfaces which is required to downscale the climate datasets from coarser scale into regional scales. In the case of nested models, the LBC is provided by the parent domain for its child. The errors produced by the LBC have been disputed by previous studies, however, recommendations were also suggested to minimize the errors [2], [10-12] including the selection of temporal and spatial resolutions. Davies [13] recently has also identified that errors produced is very small as compared to the overall errors. Though, the studies were performed for non-tropical regions, thus, least information on the tropical regions can be found [2], [10-13]. Based on this fact, site-specific study is encouraged to choose the best LBC for tropical climate modelling.

This study is conducted to analyse the performance of two different LBC in verifying the effects of urbanization on the thermal variation of a tropical urban climate like the Kuala Lumpur City. These two LBC were equipped with different resolutions are freely downloaded in the National Centre of Atmospheric Research (NCAR) archive. The result of this study can be be used as a guide for similar climate background. Future studies within the tropical regions are recommended to illuminate the errors resulted by applying the LBCs particularly when high resolutions climate modelling is required.

Over thousands of years, natural factors are the key drivers of climate changes such as volcanic activities and solar output variations [14]. However, in 1700s, urbanization was recognized as one of the significant factors of climate changes after the Industrial Revolution. The rate of the climate changes is also found to be at its highest peak in the $21^{\text {st }}$ century due the rapid increment of human population. $[14,15]$. In order to cater the human needs, many developments were erected and eventually turning many regions of the world into concrete jungles. It is indeed for human well-being as many job opportunities and better facilities are provided in the urbanized areas. The increment of the human population also resulted in the vast migration from rural to urban areas for better living [16]. Ironically, the urbanization has also turning the urban areas into heat islands when it becomes uncontrollable.

The urban thermal study has long been started [1720]. Urban areas have been proven to degrade the climate condition in global and regional scales by elevating the ambient temperature by many studies [21-25]. The centre of the urban areas tends to have higher temperature compared to its outskirts. The intensity of the temperature decreases in areas further away from the centre of the urbanized area. This has been proven by many large-scaled studies on urban expansions. Most of these studies monitor the temporal and spatial changes of the urban areas as well as its relationships to its thermal environment. Recent studies have confirmed that the urban expansion; using spatial and temporal monitoring, contribute to the increase of the ambient temperature [22], [26-29]. Therefore, there is a need to investigate and scrutinize the reasons of these negative consequences behind the urbanization process.

Various studies on urban areas with more details have been conducted to identify the reasons behind the heating of the urban areas. Most of them suggest that the greatest 
contributing factor of the urban heating is the increment of impervious surfaces by the man-made features such as buildings and pavements $[17,30]$. The impervious surfaces tend to store more heat energy depending on their characteristics. The surface materials such as asphalt accounted as the contributor of heat energy by the impervious surfaces. Low albedo surfaces which fail to reflect the heat back on to the atmosphere during daytime makes the heat to be stored as latent heat by the urban features [31]. The heat will be released back into the atmosphere making the night time to be warm [32, 33]. This situation is worsened by limited sky view factor (SVF) which decreases the rate of heat release during night time [34].

High density of buildings is also one of the contributing factors to the degradation of climate in urban areas. Cities with high density of buildings will not permit the wind flows into the city which degrade the air ventilation system efficiency $[35,36]$. The disruption of the wind will accumulate the heat and pollution within the cities since the strength of the wind is weaken by the building facades or surface roughness making the wind unable to sweep the heat and polluted air away from the city [37]. Other than that, high density buildings will limit the SVF and contribute to the night time warming as mentioned earlier. However, large SVF brings more heat during day time as the effects of shadow will be lessened [34]. The optimization of the SVF amount should be quantified for ideal heat release and shadow effects for positive impact towards the climate. Based on these, it is determined that urbanization is affecting the climate significantly. Since regional climate model is very crucial to study urbanization effects towards the climate, this study was also conducted to investigate the performance of the LBCs in determining effects of urbanization towards the variation of thermal environment.

\section{Methods}

In this study, a numerical model called WRF-ARW simulation model was employed to reproduce the air surface temperature of the study area. Remote sensing technique was used to extract the built-up area and GIS was utilized as the main analysis platform for the entire study. Parametric statistical methods were employed to analyse the performances of both LBCs. The methods employed for the study are discussed in the following sections.

\subsection{WRF-ARW Simulation}

In this study, the two global LBCs, NCEP FNL Operational Model for Global Tropospheric Analyses and NCEP GDAS/FNL for Global Tropospheric Analyses and Forecast Grids were chosen for comparison and denoted as Simulation 1 and Simulation 2 respectively. The characteristics of the LBCs' utilized are presented in Table 1. These datasets were utilized due to their wide applications to resemble tropical conditions for regional climate downscaling [38-42]. The datasets were dated $17^{\text {th }}$ April 2017 corresponding to the date of the Landsat satellite images employed during this study. The date chosen was within the inter-monsoon season phase when less synoptic forcing occurred as compared to monsoon seasons and another inter-monsoon season in October [43].

Table 1. LBCs' characteristics.

\begin{tabular}{|c|c|c|}
\hline & $\begin{array}{l}\text { NCEP FNL } \\
\text { Operational Model } \\
\text { Global Tropospheric } \\
\text { Analyses, continuing } \\
\text { from July } 1999\end{array}$ & $\begin{array}{l}\text { NCEP GDAS/FNL } \\
\text { Global Tropospheric } \\
\text { Analyses and } \\
\text { Forecast Grids }\end{array}$ \\
\hline Data Type & Grid & Grid \\
\hline Data Format & $\begin{array}{l}\text { WMO_GRIB1 } \\
\text { WMO_GRIB2 }\end{array}$ & WMO_GRIB2 \\
\hline $\begin{array}{l}\text { Temporal } \\
\text { Resolution }\end{array}$ & 6 hours & 3 hours \\
\hline $\begin{array}{l}\text { Spatial } \\
\text { (Grid) } \\
\text { Resolution }\end{array}$ & $1^{\circ} \times 1^{\circ}$ & $0.25^{\circ} \times 0.25^{\circ}$ \\
\hline $\begin{array}{l}\text { Data } \\
\text { Coverage }\end{array}$ & $\begin{array}{c}\text { From } 0 \mathrm{E} \text { to } 359 \mathrm{E} \text { and } \\
90 \mathrm{~N} \text { to } 90 \mathrm{~S}\end{array}$ & $\begin{array}{c}\text { From } 0 \mathrm{E} \text { to } 359 \mathrm{E} \text { and } \\
90 \mathrm{~N} \text { to } 90 \mathrm{~S}\end{array}$ \\
\hline
\end{tabular}

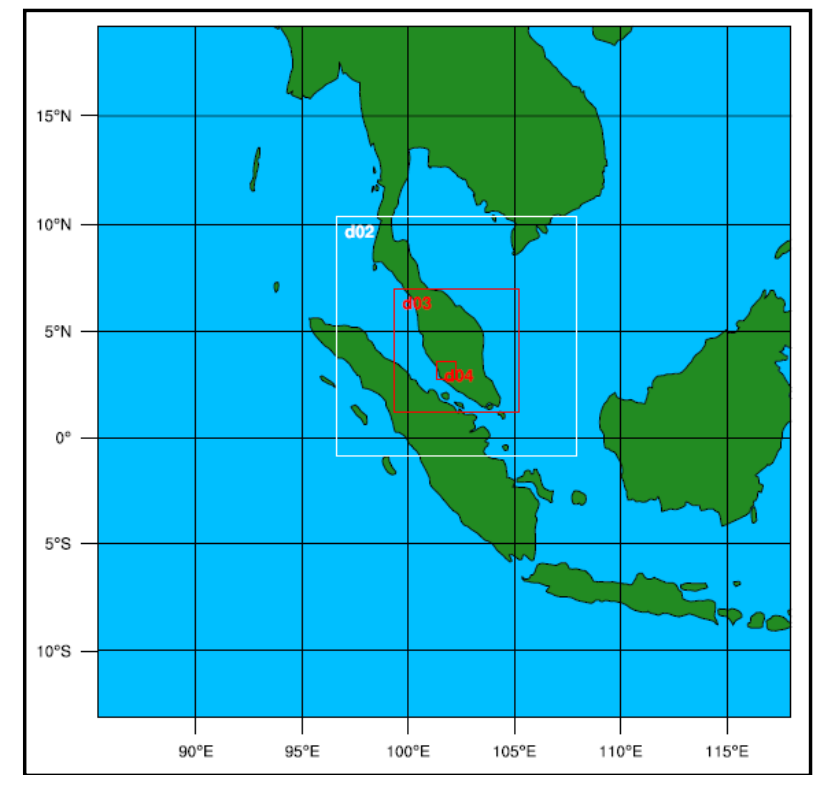

Fig. 1. The domains design and setup.

The regional modelling process was performed using WRF-ARW simulation to downscale the datasets. Domains with three nests were designed with the grid size of $37.5 \mathrm{~km}(40 \times 40), 12.5 \mathrm{~km}(88 \times 88), 2.5 \mathrm{~km}(201 \times 201)$ and $0.5 \mathrm{~km}(151 \times 151)$ to reproduce the near surface temperature. The grid dimensions were designed in easting and northing direction as shown in the parentheses. Figure 1 shows the domain designed for this study. Based on the figure, the four domains were designed using the same centre which focuses on the Kuala Lumpur location. This 
is to provide relaxation zone for the domain edges to reduce the errors that might resulted by employing LBC [8]. The fourth domain (D04) covered the Klang Valley region where the study area is located, and the largest domain was designed to cover parts of Southeast Asia (D01).

Table 2. Physics schemes used during the simulation process.

\begin{tabular}{ll}
\hline \multicolumn{1}{c}{ Physic Option } & \multicolumn{1}{c}{ Physic Scheme } \\
\hline Microphysics & $\begin{array}{l}\text { WRF Single-Moment 3- } \\
\text { class scheme }\end{array}$ \\
Longwave Radiation & $\begin{array}{l}\text { RRTM scheme } \\
\text { Shortwave Radiation }\end{array}$ \\
Surface Layer & Dudhia scheme \\
Land Surface & Noah Land Surface Model \\
Planetary Boundary Layer & Yonsei University \\
Cumulus Parameterization & Kain-Fritsch \\
\hline
\end{tabular}

The WRF-ARW offers multiple physics options, simple as well as complicated schemes. Thus, a well-tried scheme combination was employed in configuring the physics and dynamics of the targeted area. The scheme combination used in the model as shown in Table 2. The study has employed the same domain design and scheme combinations for Simulation 1 and Simulation 2. The physics schemes chosen was a set of well-tried options conducted by [44] that successfully simulate the diurnal air surface temperature of the Kuala Lumpur city with the accuracy of over $90 \%$ agreements with the ground station observations provided by the Malaysian Meteorological Department (MMD). Using the same physics schemes as the study, the diurnal air surface temperature of the study area was simulated. The schemes have also been employed by many studies to remodel the actual urban climate condition within tropical countries [44-47].

\subsection{Remotely-Sensed Data Extraction}

This study has utilized the Landsat 8 Operational Land Imager (OLI) satellite image to extract the urbanized area. The image employed was dated 17th April 2017 during the first inter-monsoon season of the year. The image was also chosen due to a clear sky view that reduce the chance of atmospheric errors to occur [44]. The radiometric calibration procedure was conducted to correct the image to ensure it is free from radiometric errors [48]. The process converts the pixel values into surface reflectance as shown in Equation 1. Then, sun angle displacement was corrected using Equation 2.

$$
\rho \lambda^{\prime}=M_{\rho} \times Q_{C A L}+A_{L}
$$

where $\varrho \lambda^{\prime}=$ surface reflectance without sun angle correction

$$
\begin{aligned}
\mathrm{M} \varrho= & \text { band-specific multiplicative rescaling factor } \\
& \text { from metadata } \\
\mathrm{Q}_{\mathrm{CAL}}= & \text { Quantized and calibrated standard product } \\
& \text { pixel value } \\
\mathrm{A}_{\varrho}= & \begin{array}{l}
\text { band-specific additive rescaling factor from } \\
\text { metadata }
\end{array}
\end{aligned}
$$

$$
\rho \lambda=\frac{\rho \lambda^{\prime}}{\cos \left(\Theta_{S Z}\right)}=\frac{\rho \lambda^{\prime}}{\sin \left(\Theta_{S E}\right)}
$$

where $\theta_{\mathrm{SZ}}=$ Local sun elevation angle

$\theta_{\mathrm{SE}}=$ Local solar zenith angle

A combined algorithm developed by [49] was conducted to extract the built-up areas (urbanized areas). The algorithm is suitable to be used since the area of study share the same climate experiences as the Kuala Lumpur City. The study [49] suggested that the original NDBI algorithm developed derived by [50] should be corrected. Supported by [51]-[54], the confusion to separate the builtup areas from green cover and water features were suggested to be eliminated or reduced using Normalized Difference Vegetation Index (NDVI) and Modified Normalized Difference Water Index (MNDWI). Principal Component Analysis (PCA) is also suggested to be employed to assign the best pixel values for the MIR wavelength. The algorithm of NDBI, NDVI and MNDWI are shown as Equation 4, Equation 5 and Equation 6 respectively.

$$
\text { Built }- \text { up Area }=N D B I-N D V I-N D W I
$$

$$
N D B I=\frac{(P C A \text { Band } 6,7+P C A \text { Band 10,11) }- \text { Band } 5}{(\text { PCA Band 6,7 + PCA Band 10,11) + Band } 5}
$$

$$
\begin{gathered}
\text { NDVI }=\frac{\text { Band } 5-\text { Band } 4}{\text { Band } 5+\text { Band } 4} \\
M N D W I=\frac{\text { Band } 3-\text { Band } 7}{\text { Band } 3+\text { Band } 7}
\end{gathered}
$$

\subsection{Model Validation}

In this study, three statistical error indices namely mean absolute error (MAE), root mean square error (RMSE) and linear agreement were used to evaluate the performance of the selected LBCs during simulation process. The air surface temperature layer produced via the simulation were compared against the ground data observed by the Malaysian Meteorological Department (MMD) stations. As shown in Fig. 2, the observation of three MMD ground stations were utilized namely MARDI Serdang station, FRIM Kepong station and 
Subang station. The locations of these ground stations are presented in Fig. 2.

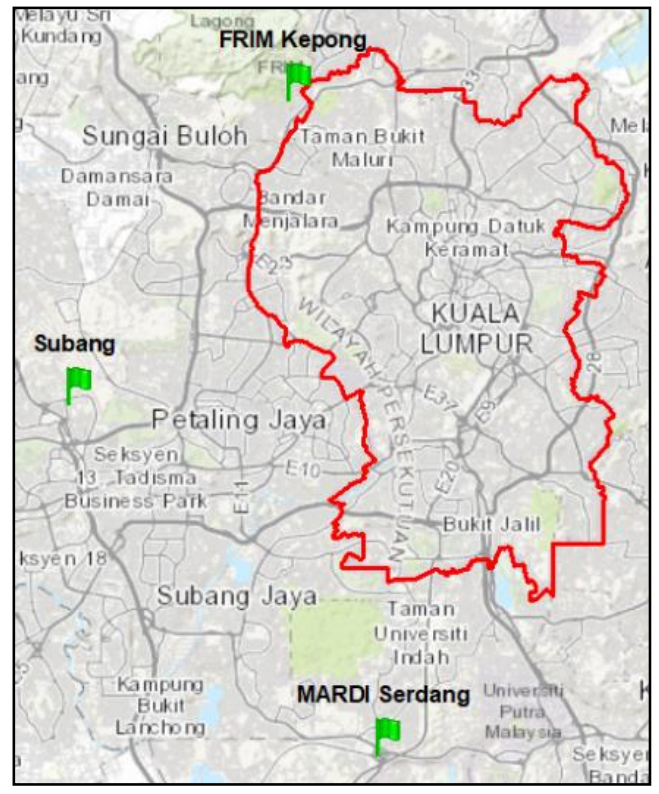

Fig. 1. Location of MMD ground stations.

\subsection{Data Sampling and Inferential Statistics}

Data filtration was conducted to ensure that the original data was free from outliers. As suggested by [55], [56], the process was carried out based on quartiles and boxplots to exclude the outliers. Prior to data analysis, the data was examined to identify the nature of the data distribution. The study has utilized the whole data samples and it is found that the data was approximately normaldistributed. This was indicated by the ratio of kurtosis and skewness value against the standard error. Thus, a series of parametric statistical approach was selected. Two statistical approach were used namely Pearson's correlation test; to examine the interaction of urbanized areas with the air surface temperature, and one-way Analysis of Variance (ANOVA); to determine whether the impact is significant. The one-way ANOVA was conducted with the control of Welch's and Brown-
Forsythe's test to ensure the error that may resulted can be reduced.

\section{Result and analysis}

The results and findings of this study are discussed into two parts; 1) the simulation performance and 2) the urbanization impacts towards the thermal environment of the Kuala Lumpur City. The results and findings are presented as follows:

\subsection{Simulations Performance}

The values of MAE, RMSE and $\mathrm{R}^{2}$ for the two simulations are presented in Table 3 . The results show that Simulation 2 excels Simulation 1 in reproducing the air surface temperature of the study area. It is based on the value of MAE of $\pm 1^{\circ} \mathrm{C}, \mathrm{RMSE}$ of $\pm 1.4^{\circ} \mathrm{C}$ and $\mathrm{R}^{2}$ of 0.881 compared to Simulation 1 which has slightly lower results; the value of $\mathrm{MAE}$ is $\pm 1.5^{\circ} \mathrm{C}, \mathrm{RMSE}$ is $\pm 1.8^{\circ} \mathrm{C}$ and $\mathrm{R}^{2}$ is 0.763 . Figure 3 shows the diurnal pattern of the nearsurface temperature of the city. Based on the figure, it is found that similar pattern was identified. Both simulations were found to underestimate the near-surface temperature in MARDI Serdang and Subang. However, both models were found to overestimate the near-surface profile during morning hours. On the other hand, both models tend to overestimate the temperature in FRIM Kepong despite some underestimation during the highest temperature readings. Through the study also, larger residuals were identified in Simulation 1 especially when the temperature was rapidly increase.

Table 3. MAE, RMSE and $\mathrm{R}^{2}$ of Simulation 1 and Simulation 2.

\begin{tabular}{lll}
\hline & $\begin{array}{l}\text { NCEP FNL } \\
\text { Operational Model } \\
\text { Global Tropospheric } \\
\text { Analyses, continuing } \\
\text { from July 1999 } \\
\text { (Simulation } 1)\end{array}$ & $\begin{array}{l}\text { NCEP GDAS/FNL } \\
\text { Global Tropospheric } \\
\text { Analyses and } \\
\text { Forecast Grids } \\
\text { (Simulation 2) }\end{array}$ \\
\hline MAE & $\pm 1.5^{\circ} \mathrm{C}$ & $\pm 1.0^{\circ} \mathrm{C}$ \\
RMSE & $\pm 1.8^{\circ} \mathrm{C}$ & $\pm 1.4^{\circ} \mathrm{C}$ \\
$\mathrm{R}^{2}$ & 0.763 & 0.881 \\
\hline
\end{tabular}
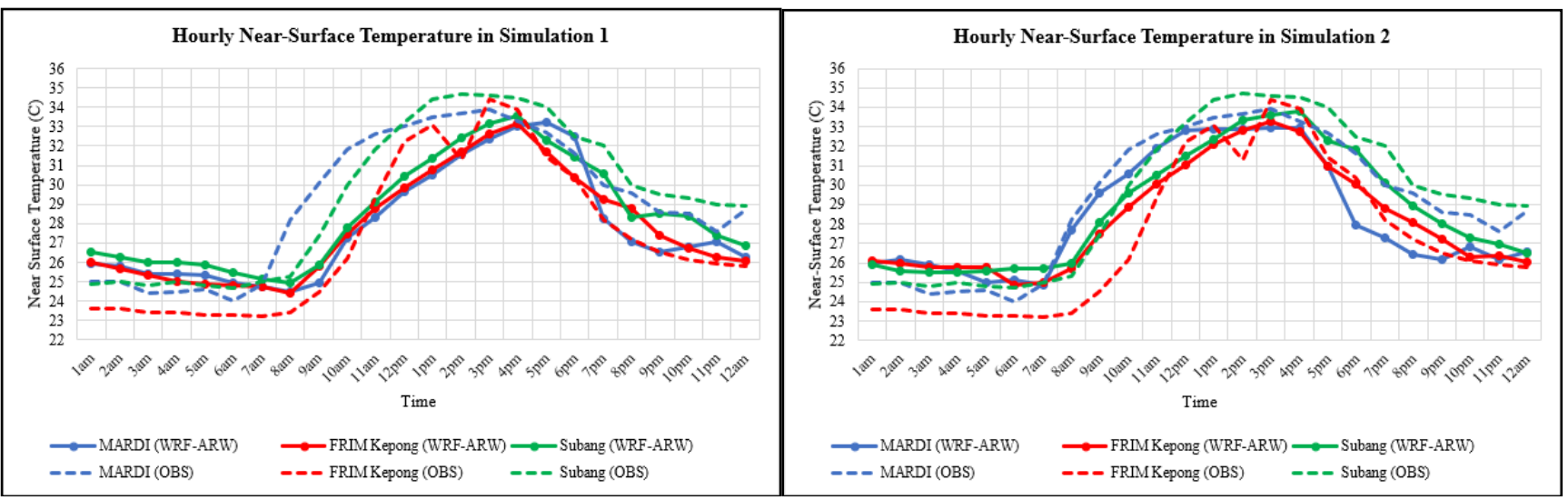

Fig. 2. Hourly profiles of near-surface temperature for both simulations in three different stations. 


\subsection{Urbanization Effects}

3.2.1. Spatial distribution of urbanized areas and nearsurface temperature profile

Figure 4 shows the distribution of built-up areas within the Kuala Lumpur City. It was found that, the city was dominated by built-up areas by approximately $85 \%$ of area coverage. The highest built area percentage found to be $99.5 \%$ indicating the imperviousness of the surface area. The lowest built-up percentage is $0 \%$ indicating there are no built-up coverage found within the area. Most of the highest built-up percentages are found in Sentul whereas the lowest built-up percentages were found in natural forest reserve such as Bukit Tabur, Bukit Besi and Bukit Gasing.

This study has identified that the northern, southern and central regions of the Kuala Lumpur City have higher built-up area percentages as compared to other regions. These areas are developed areas such as Sentul (residential), Kepong (industries), Central of Kuala Lumpur (business) and Bukit Bintang (business). These developed areas are expected to have higher near-surface temperature as compared to other less developed areas. Bukit Tunku and Mont Kiara are expected to have lower near-surface temperatures as the distribution of built-up areas are lower.

Spatial distribution of the daily mean air surface temperature of the Kuala Lumpur City produced by Simulation 1 and Simulation 2 are depicted in Figure 5. The lowest daily mean air surface temperature was $27.1^{\circ} \mathrm{C}$ and the highest value was $29.9^{\circ} \mathrm{C}$. In Simulation 2, a close resemblance was identified. The lowest daily mean air surface temperature was $27.0^{\circ} \mathrm{C}$ and the highest mean temperature was $29.9^{\circ} \mathrm{C}$. Based on Figure 5 also, the study has determined that the spatial distribution of both simulations was similar. In each simulation, the eastern regions own lower daily mean air surface temperature whereas the northern and southern regions experienced higher temperature variation.
In deeper examination of Figure 5, the lowest air surface temperature was found in the mountainous regions of Bukit Tabur which located in the north-eastern region of the city. Mont Kiara, Bukit Tunku and Bukit Besi are other areas that own lower daily mean air surface temperatures. Sri Petaling has identified to have the highest daily mean air surface temperature which located in the south-western region of the city. Other regions with high daily mean air surface temperature are Kepong, Danau Kota, Bukit Bintang, Chow Kit, Kampung Baru and Segambut. Based on these results, it can be concluded that urbanized areas contribute to the increase of the air surface temperature within the Kuala Lumpur City.

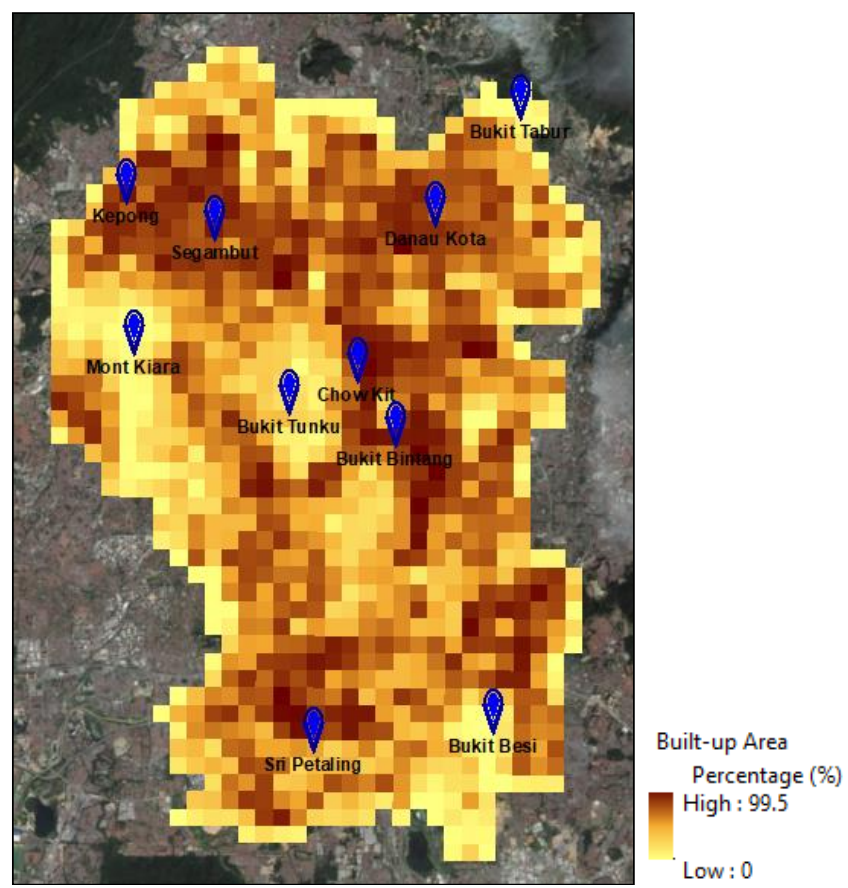

Fig. 3. Spatial distribution of built-up area percentage in the Kuala Lumpur City.

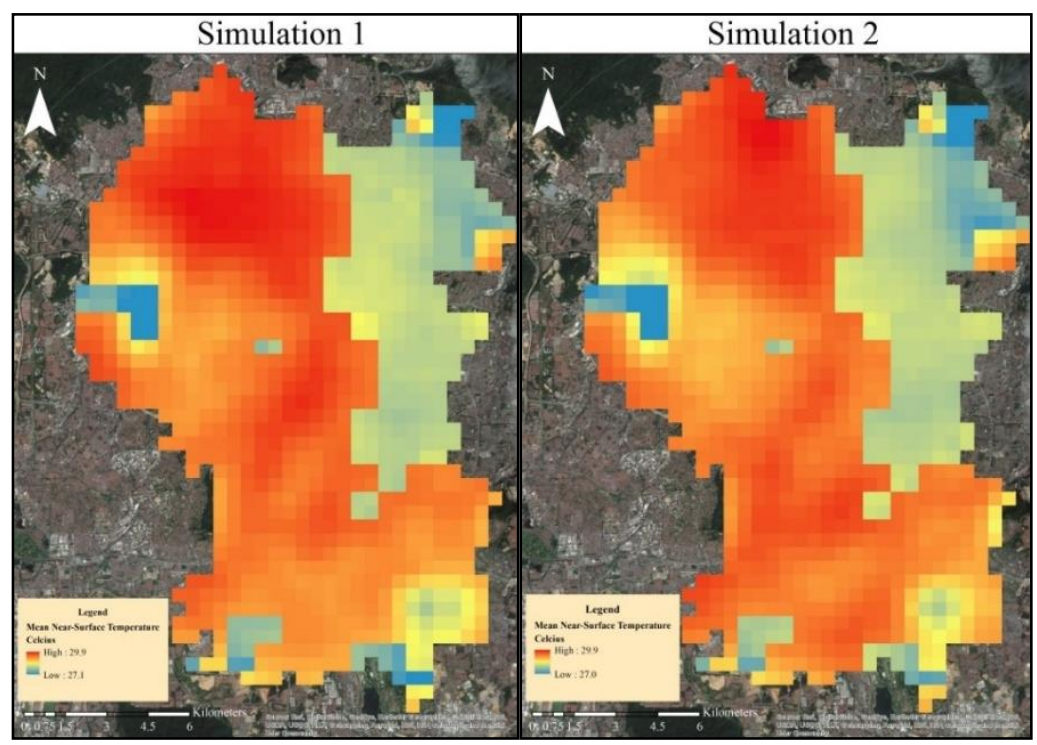

Fig. 4. Spatial distribution of the daily mean near-surface temperature for Simulation 1 and Simulation 2. 


\subsubsection{Pearson's correlation test result}

The comparison made has determined that a close result was obtained for Simulation 1 and Simulation 2 . Based on the Pearson's correlation test, the correlation between the daily mean air surface temperature and builtup percentage for Simulation 1 and Simulation 2 were 0.662 and 0.648 respectively with a positive relationship. The relationship was indicated by the increasing trendline as portrayed in Figure 6. As shown in the figure, the distribution of the points in the graph is closer in Simulation 2 which explained the slightly higher result. Thus, in presenting the correlation between the daily mean air surface temperature and built-up area percentage, both simulations gave a very similar result. Therefore, both LBC can be employed for similar climate background studies.
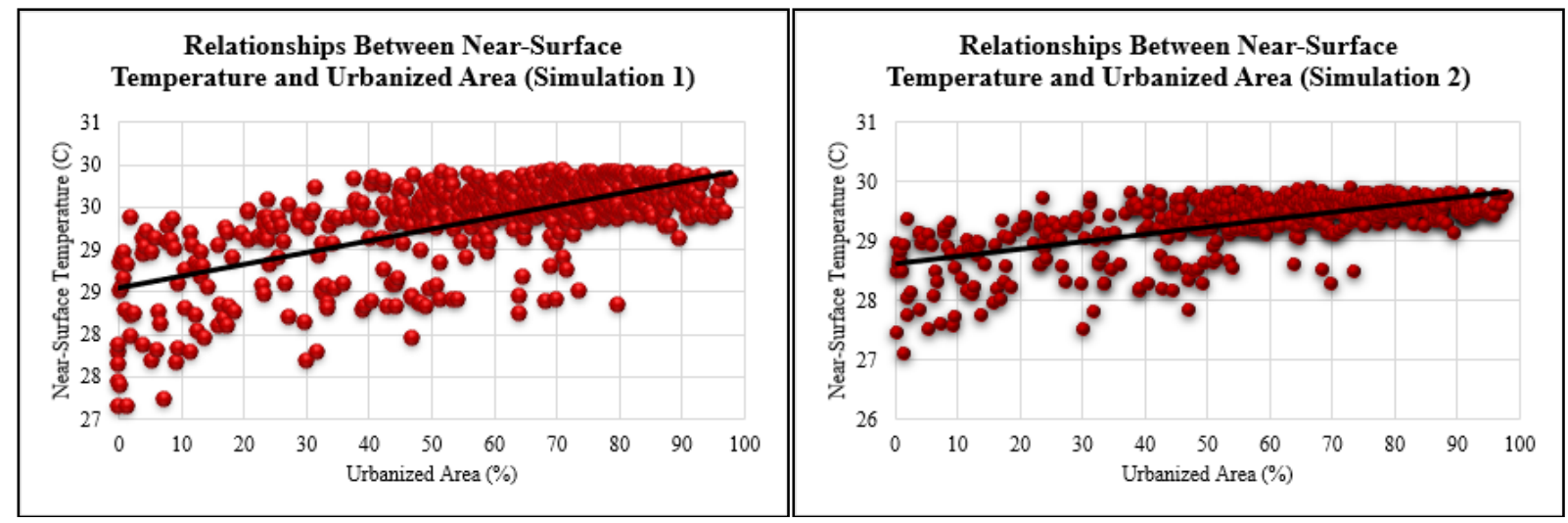

Fig. 5. Trendline of near-surface temperature and urbanized area for Simulation 1 and Simulation 2.

The current results obtained through this study support the findings of previous researches. In this study, it was identified that the urbanization was affecting the thermal variation of the Kuala Lumpur City. This advocates that urbanized areas is responsible in the increase of the near-surface temperature of the city; the higher the built-up coverage percentage, the higher the air surface temperature.

\subsubsection{One-way ANOVA test result}

The investigation of the performance of both LBCs employed was further by conducting one-way ANOVA procedures. A similar test was performed for both simulations. Using the daily mean air surface temperature produced, this study has identified that both models a similar result; where both test rejecting the null hypothesis which suggesting the same conclusion. The effects of urbanization towards the near-surface temperature were identified as significant as the $\mathrm{p}$-value rejected the null hypothesis of one-way ANOVA. Through the test, it was confirmed that there was at least one significant difference between the classes of data samples. This result suggests that the changes in the built-up area percentage will significantly affect the near-surface temperature value within the Kuala Lumpur City.

Previously, many studies have documented that rapid urbanization leads to fast conversion of green covers such as natural forest and croplands which is the prime cause to the rise in the surrounding temperature that leads to the formation of UHI [25], [26]. The green covers and croplands are replaced with built-up areas which increase the heat capacity storage. This will lead to the increase of heat release into the air, making the surrounding temperature to be hotter. The present study also discovered similar phenomena occurred in the Kuala Lumpur City as documented by previous studies. The region with high built-up areas experienced high temperature as compared to the area with less built-up areas $[40,43]$.

\section{Conclusion}

The performance of two LBCs with different spatial and temporal resolutions in initializing the boundary conditions in WRF-ARW numerical simulation were analysed in this study. The performance was tested in regenerating the near-surface temperature of a tropical city in Malaysia. The study has identified that the LBC with higher spatial and temporal resolution gave higher performance for regional downscaling. However, this study has also identified that both LBCs offers similar performance, thus, both LBCs are suitable to be utilized in reproducing the near-surface temperature of tropical cities. Future studies regarding this matter are urged with separate analysis on spatial and temporal resolutions impacts in regenerating the tropical urban climate condition.

As Malaysia envisions its cities to be climatic-friendly in the near future, implementation of the urban climatic aspect should be emphasized in urban planning process. In line with the National Policy on Climate Change and the National Green Technology Policy introduced by the government, consideration on the urban climatic aspect 
require active participation from the multi-disciplines experts. At the moment, international efforts in addressing the importance of sustainable development are also evident through many programs such as the Global Cool Cities Alliance (GCCA), World Urban Forum (WUF) and New Urban Agenda by United Nations which encourage the countries worldwide to join the alliance to combat the climate change impacts on urban regions.

\section{Acknowledgements}

The authors would like to express their gratitude to the Universiti Teknologi MARA (UiTM) for funding this project under Geran Bestari Perdana 600-IRMI/DANA 5/3 BESTARI (P) (074/2018).

\section{References}

[1] IPCC, "Climate Change 2001: Synthesis Report," 2001.

[2] A. Amengual, R. Romero, V. Homar, C. Ramis, and S. Alonso, "Impact of the lateral boundary conditions resolution on dynamical downscaling of precipitation in Mediterranean Spain," Clim. Dyn., vol. 29, no. 5, pp. 487-499, 2007.

[3] F. Giorgi and L. Mearns, "Introduction to special section: regional climate modelling revisited," J. Geophys. Res., vol. 104, pp. 6335-6352, 1999.

[4] S. Y. Hong and J. O. J. Lim, "The WRF-ARW single moment 6-class microphysics scheme (WSM6)," J. Korean Meteorol. Soc., vol. 42, no. 2, pp. 129-151, 2006.

[5] X.-M. Hu, J. W. Nielsen-Gammon, and F. Zhang, "Evaluation of three planetary boundary layer schemes in the WRF model," J. Appl. Meteorol. Climatol., vol. 49, pp. 1831-1844, 2010.

[6] J. A. Ruiz-Arias, J. Dudhia, F. J. Santos-Alamillos, and D. Pozo-Vázquez, "Surface clear-sky shortwave radiative closure intercomparisons in the Weather Research and Forecasting model," J. Geophys. Res. Atmos., vol. 118, no. 17, pp. 9901-9913, 2013.

[7] A. Arakawa, "The cumulus parameterization problem: Past, present, and future," J. Clim., vol. 17, no. 13, 2004.

[8] NCAR, Weather Research and Forecasting: $A R W$ version 3 modelling system user's guide January 2016. 2016.

[9] P. A. Jiménez, J. Dudhia, J. F. González-Rouco, J. Navarro, J. P. Montávez, and E. García-Bustamante, "A revised scheme for the WRF surface layer formulation," Mon. Weather Rev., vol. 140, no. 3, pp. 898-918, 2012.

[10] T. Warner, R. Peterson, and R. Treadon, "A tutorial on lateral boundary conditions as a basic and potentially serious limitation to regional numerical weather prediction," Bulletin of the American Meteorological Society, pp. 2599-2617, 1997.

[11] B. Denis, R. Laprise, and D. Caya, "Sensitivity of a regional climate model to the resolution of the lateral boundary conditions," Clim. Dyn., vol. 20, pp. 107126, 2002.
[12] M. Dimitrijevic and R. Laprise, "Validaion of the nesting technique in a regional climate model and sensitivity tests to the resolution of the lateral boundary conditions during summer," Clim. Dyn., vol. 25, pp. 555-580, 2005.

[13] T. Davies, "Lateral boundary conditions for limited area models," Q. J. R. Meteorol. Soc., vol. 140, pp. 185196, 2014.

[14] EPA, "Climate change indicators: weather and climate," United States Environmental Protection Agency, 2016. [Online]. Available: https://www.epa.gov/climate-indicators/weatherclimate (accessed November 5, 2018).

[15] D. N. Asimakopoulos, "Climate and climate change," in Energy and Climate in the Urban Built Environment, 2nd ed., M. Santamouris, Ed. New York, USA: Routledge Taylor and Francis Group, 2011, pp. 1932.

[16] G. Siciliano, "Urbanization strategies, rural development and land use changes in China: A multiple-level integrated assessment," Land Use Policy, vol. 29, no. 1, pp. 165-178, 2012.

[17] A. Mohajerani, J. Bakaric, and T. Jeffrey-Bailey, "The urban heat island effect, its causes, and mitigation, with reference to the thermal properties of asphalt concrete," J. Environ. Manage., vol. 197, pp. 522-538, 2017.

[18] M. Hebbert, "Urban climate climatology for city planning in historical perspective," Urban Clim., vol. 10, no. 2014, pp. 1-12, 2014.

[19] D. Argüeso, J. P. Evans, L. Fita, and K. J. Bormann, "Temperature response to future urbanization and climate change," Clim. Dyn., vol. 42, no. 7-8, pp. 2183-2199, 2014.

[20] M. P. McCarthy, M. J. Best, and R. A. Betts, "Climate change in cities due to global warming and urban effects," Geophys. Res. Lett., vol. 37, no. 9, pp. 1-5, 2010.

[21] B. Y. Tam, W. A. Gough, and T. Mohsin, "The impact of urbanization and the urban heat island effect on day to day temperature variation," Urban Clim., vol. 12, pp. 1-10, 2015.

[22] L. W. A. Van Hove, C. M. J. Jacobs, B. G. Heusinkveld, J. A. Elbers, B. L. Van Driel, and A. A. M. Holtslag, "Temporal and spatial variability of urban heat island and thermal comfort within the Rotterdam agglomeration," Build. Environ., vol. 83, pp. 91-103, 2015.

[23] M. Srivanit, K. Hokao, and V. Phonekeo, "Assessing the impact of urbanization on urban thermal environment: A case study of Bangkok Metropolitan,' Int. J. Appl. Sci. Technol., vol. 2, no. 7, pp. 243-256, 2012.

[24] Y. Xiong, S. Huang, F. Chen, H. Ye, C. Wang, and C. Zhu, "The impacts of rapid urbanization on the thermal environment: A remote sensing study of Guangzhou, South China," Remote Sens., vol. 4, no. 7, pp. 2033-2056, 2012.

[25] S. N. A. Buyadi, W. M. N. W. Mohd, and A. Misni, 
"Impact of land use changes on the surface temperature distribution of area surrounding the National Botanic Garden, Shah Alam," Procedia - Soc. Behav. Sci., vol. 101, pp. 516-525, 2013.

[26] A. Polydoros and C. Cartalis, "Assessing the impact of urban expansion to the state of thermal environment of peri-urban areas using indices," Urban Clim., vol. 14, pp. 166-175, 2015.

[27] Y. Cui, D. Yan, T. Hong, and J. Ma, “Temporal and spatial characteristics of the urban heat island in Beijing and the impact on building design and energy performance," Energy, vol. 130, pp. 286-297, 2017.

[28] M. Srivanit and H. Kazunori, "The influence of urban morphology indicators on summer diurnal range of urban climate in Bangkok Metropolitan Area, Thailand," Int. J. Civ. Environ. Eng., vol. 11, no. 5, pp. 34-46, 2011.

[29] R. Anniballe, S. Bonafoni, and M. Pichierri, "Spatial and temporal trends of the surface and air heat island over Milan using MODIS data," Remote Sens. Environ., vol. 150, pp. 163-171, 2014.

[30] Y. Wang, Q. Zhan, and W. Ouyang, "Impact of urban climate landscape patterns on land surface temperature in Wuhan, China," Sustainability, vol. 9, no. 10 , p. 1700, 2017.

[31] S. A. Salleh, Z. Abd Latif, W. M. N. Wan Mohd, and A. Chan, "Albedo pattern recognition and timeseries analyses in Malaysia," Int. Arch. Photogramm. Remote Sens. Spat. Inf. Sci. - ISPRS Arch., vol. 39, no. September, pp. 235-240, 2012.

[32] S. D. Arifwidodo and T. Tanaka, "The Characteristics of Urban Heat Island in Bangkok, Thailand," Procedia - Soc. Behav. Sci., vol. 195, pp. 423428, 2015.

[33] A. Shaharuddin, M. H. Noorazuan, W. Takeuchi, and A. Noraziah "The effects of Urban Heat Islands on Human Comfort: A Case of Kalng Valley Malaysia," Glob. J. Adv. Pure Appl. Sci., vol. 2, no. April, pp. 1-8, 2014.

[34] G. Guo, X. Zhou, Z. Wu, R. Xiao, and Y. Chen, "Characterizing the impact of urban morphology heterogeneity on land surface temperature in Guangzhou, China," Environ. Model. Softw., vol. 84, pp. 427-439, 2016.

[35] E. Ng, C. Yuan, L. Chen, C. Ren, and J. C. H. Fung, "Improving the wind environment in high-density cities by understanding urban morphology and surface roughness: A study in Hong Kong," Landsc. Urban Plan., vol. 101, no. 1, pp. 59-74, 2011.

[36] P. Coseo and L. Larsen, "How factors of land use/land cover, building configuration, and adjacent heat sources and sinks explain Urban Heat Islands in Chicago," Landsc. Urban Plan., vol. 125, pp. 117-129, 2014.

[37] T. Kubota and S. Ahmad, "Wind environment evaluation of neighborhood areas in major towns of Malaysia," J. Asian Archit. Build. Eng., no. May, pp. 199-206, 2006.

[38] K. I. Morris, "Effect of vegetation and waterbody on the garden city concept: An evaluation study using a newly developed city, Putrajaya , Malaysia," Comput., Environ. Urban Syst., vol. 58, pp. 39-51, 2016.

[39] A. Trihamdani, H. Lee, T. Kubota, and T. Phuong, "Configuration of green spaces for urban heat island mitigation and future building energy conservation in Hanoi Master Plan 2030," Buildings, vol. 5, no. 3, pp. 933-947, 2015.

[40] N. A. Isa, W. M. N. Wan Mohd, and S. A. Salleh, "The effects of built-up and green areas on the land surface temperature of the Kuala Lumpur City," in International Arcbives of the Photogrammetry, Remote Sensing and Spatial Information Sciences - ISPRS Archives, 2017, vol. 42, no. 4W5, pp. 107-112.

[41] F. J. L. Lima, F. R. Martins, E. B. Pereira, E. Lorenz, and D. Heinemann, "Forecast for surface solar irradiance at the Brazilian Northeastern region using NWP model and artificial neural networks," Renew. Energy, vol. 87, pp. 807-818, 2016.

[42] Q. Van Doan, H. Kusaka, and Q. B. Ho, "Impact of future urbanization on temperature and thermal comfort index in a developing tropical city: Ho Chi Minh City," Urban Clim., vol. 17, pp. 20-31, 2016.

[43] M. C. G. Ooi et al., "Comparison of WRF local and nonlocal boundary layer physics in Greater Kuala Lumpur, Malaysia," in IOP Conference Series: Earth and Environmental Science, 2018, pp. 1-7.

[44] N. A. Isa, W. M. N. Wan Mohd, S. A. Salleh, and M. C. G. Ooi, "The effects of green areas on air surface temperature of the Kuala Lumpur city using WRFARW modelling and Remote Sensing technique," IOP Conf. Ser. Earth Environ. Sci., vol. 117, pp. 1-8, 2018.

[45] K. I. Morris, A. Chan, S. A. Salleh, M. C. G. Ooi, M. Y. Oozeer, and Y. A. Abakr, "Numerical study on the urbanization of Putrajaya and its interaction with the local climate, over a decade," Urban Clim., vol. 16, pp. 1-24, 2016.

[46] S. A. Salleh, Z. A. Latif, A. Chan, K. I. Morris, M. C. G. Ooi, and W. M. N. W. Mohd, "Weather Research Forecast (WRF) modification of land surface albedo simulations for urban Near Surface Temperature," in International Conference on Space Science and Communication, IconSpace, 2015, pp. 243-247.

[47] J. Singh, K. Yeo, X. Liu, R. Hosseini, and J. R. Kalagnanam, "Evaluation of WRF model seasonal forecasts for tropical region of Singapore," Adv. Sci. Res., vol. 12, pp. 69-72, 2015.

[48] USGS, "Using the USGS Landsat Level-1 Data Product," Available: https://landsat. usgs.gov/using-usgs-landsat-8-product (accessed Dec. 7, 2018).

[49] S. S. Bhatti and N. K. Tripathi, "Built-up area extraction using Landsat 8 OLI imagery," GIScience Remote Sens., vol. 51, no. 4, pp. 445-467, 2014.

[50] Y. Zha, J. Gao, and S. Ni, "Use of normalized difference built-up index in automatically mapping urban areas from TM imagery," Int. J. Remote Sens., vol. 24, no. 3, pp. 583-594, 2003. 
[51] C. He, P. Shi, D. Xie, and Y. Zhao, "Improving the normalized difference built-up index to map urban built-up areas using a semiautomatic segmentation approach," Remote Sens. Lett., vol. 1, no. 4, pp. 213 221, 2010.

[52] J. I. N. a Lee, S. S. Lee, and K. H. Chi, "Development of an urban classification method using a built-up index," Sel. Top. power Syst. Remote Sens., pp. 39-43, 2010.

[53] A. Varshney, "Improved NDBI differencing algorithm for built-up regions change detection from remote-sensing data: An automated approach," Remote Sens. Lett., vol. 4, no. 5, pp. 504-512, 2013.

[54] H. Xu, "A new index for delineating built-up land features in satellite imagery," Int. J. Remote Sens., vol. 29, no. 14, pp. 4269-4276, 2008.

[55] J. Tukey, "Exploratory data analysis," Biometrical J., vol. 23, no. 4, pp. 413-414, 1977.

[56] D. Hoaglin, B. Iglewicz, and J. Tukey, "Performance of some resistant rules for outliers labeling," J. Am. Stat. Assoc., vol. 81, no. 396, pp. 991-999, 2012.

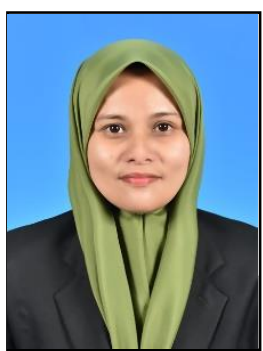

Nurul A. Isa was born in Seremban, Negeri Sembilan, Malaysia in April 1990. She obtained her first degree (BSc) in surveying science and geomatics from the Universiti Teknologi MARA, Shah Alam. She recieved her MSc degree in geographical information sciences (GIS) from the same institution in 2014. In September 2020, she was awarded a Ph.D. degree in the field of built environment with a specialization in remote sensing, GIS and climate modelling from Universiti Teknologi MARA.

She is currently a research assistant in Universiti Teknologi MARA since 2015. She also has teaching experiences for undergraduate levels for over three years as a part time lecturer. Her research interest revolves within the application of remote sensing and GIS in tropical urban climate modelling and disaster management. She also has interests in urban climate studies related to urban planning guidelines.

Gs. Dr. Isa is a professional member of the Institution of Geospatial and Remote Sensing Malaysia (IGRSM) since 2018.

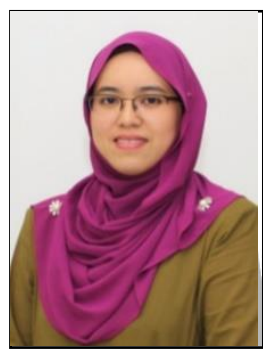

Siti A. Salleh was born in Johor, Malaysia in 1981. She received the BSc (HONS) in Geographical Information Science from University of Newcastle upon Tyne and MSc and $\mathrm{PhD}$ in Built Environment from Universiti Teknologi MARA (UiTM), Malaysia.

She has over 13 years of experience in teaching at diploma, undergraduate and postgraduate programs. She is currently an associate professor at the Centre of studies for Surveying Science and Geomatics and Head of Sustainable Technology at the Institute for Biodiversity and Sustainable Development, UiTM. She has been an active researcher in the fields of GIS, remote sensing modelling and numerical simulations application in urban studies. Her research interests lie in field of geo-informatics technology, particularly in applied remote sensing and geographical information science (GIS). She is also very keen in exploring the area of change assessments impacts of land surface process and its biophysical responses towards global, regional, and local climate conditions including the climate-terrestrial ecosystem interaction.

Sr. Dr. Salleh is a member of Royal Institution of Surveyors Malaysia (RISM), International Society of Photogrammetry and Remote Sensing (ISPRS), and Member of IEEE Geoscience and Remote Sensing Society Malaysia Chapter (IEEE - GRSS Malaysia).

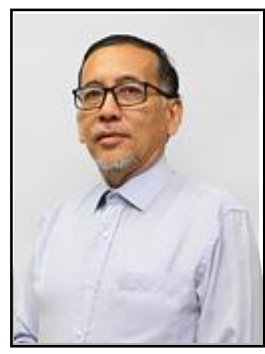

Wan M. N. Wan Mohd was born in Terengganu, Malaysia in 1960. He graduated from Institute Teknologi MARA, Shah Alam with Diploma in Land Surveying in 1980. In 1985, he received his BSc in Surveying Science (Hons) from University of Newcastle Upon Tyne, M App Science in Topographic Science (specialization in Photogrammetry and Digital Mapping) from Glasgow University in 1988 and his $\mathrm{PhD}$ from the Faculty of Science and Engineering, University of Edinburgh, UK in 1999.

He is a Professor at the Centre of Studies for Surveying Science and Geomatics, Faculty of Architecture, Planning \& Surveying (FSPU), Universiti Teknologi MARA (UiTM), Shah Alam, Malaysia. He has almost 30 years of teaching and supervising experience in the land surveying (Geomatics) field, specialising in the area of Geographical Information Science, Remote Sensing and Photogrammetry. His present research interest include: GIS and Remote Sensing for Environmental Modelling, Geospatial Technology for Climate Change, GIS for Disaster Management and Satellite-based Rainfall Precipitation Estimation.

Sr. Dr. Wan Mohd is a member of Royal Institution of Surveyors Malaysia (RISM), Steering Committee for National Geospatial Data Infrastructure Plan, National Atlas Committee, National Committee on Geoinformation and Geomatic Research, Geoinformation/Geomatics Research Committee (Working Group 1), Geoinformation/Geomatics Research Committee (Working Group 2) and Geoinformation/Geomatics Research Committee (Working Group 4). 


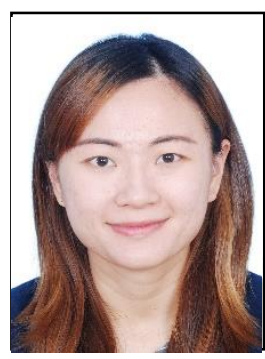

Maggie C. G. Ooi was born in Kuala Lumpur, Malaysia. She received the M.Eng degree in Chemical and Environmental Engineering and Ph.D degree in Civil Engineering from University of Nottingham Malaysia.

She was a Postdoctoral Research Fellow with National Central University Taiwan before joining the Institute of Climate Change, National University of Malaysia (UKM) as Senior Lecturer/Research Fellow in 2020. Her expertise is using chemical weather prediction models in an attempt to solve the urban and haze pollution issue. Her current project is to develop real-time air quality forecast and biomass-burning haze transportation with the numerical models.

Dr. Ooi is a registered graduate engineer for Board of Engineer Malaysia (BEM) and Institute of Engineer Malaysia (IEM). Currently, she is also elected as the standing committee member of Urban Engineering Design Special Interest Group (UEDSIG) 2020/2021 under IEM.

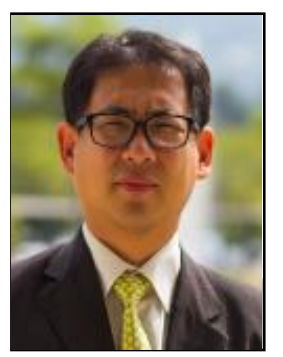

Andy Chan was born in Hong Kong. He graduated with his bachelor in engineering from the University of Hong Kong in 1993. He recieved his Ph.D degree from the same institution in 1997.

$\mathrm{He}$ is the current Dean of Engineering in University of Nottingham Malaysia Campus (UNMC). His responsibility is to oversee all research, teaching, external and operation matters of the faculty. He is a member of the UNMC management board. His area of expertise is on air pollution and computational fluid dynamics, especially towards urban climates. He is a world-known expert on recycled carbon fibres and its applications. He has studied recycled carbon fibres, its properties and applications for more than 15 years. He has successfully commercialised various products like heated garments, energy harvesters and delivery systems derived from carbon fibres and have attracted lots of interest from the industries and the media.

Dr. Chan was one of the team leader appointed by the World Health Organisation (WHO) to discover the dispersion of mechanisms of the SARS virus in the dense cityscapes in Hong Kong. He is currently the leader of the multi-national 7SEAS-NASA project (Seven South-east Asian Studies, National Aeronautics and Space Administration).

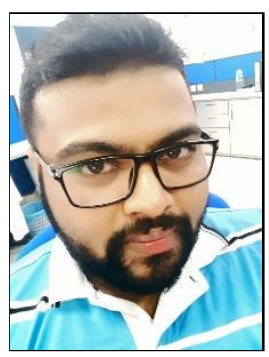

Md A. Islam was born in Bangladesh. He is currently a postgraduate students at the University of Nottingham, Malaysia. 